\title{
AN EXPERIMENTAL STUDY ON THE APPLICATION OF MICROWAVE FIXATION TO IMMUNOHISTOCHEMICAL STUDIES
}

\author{
Kenjiro YASUdA, Shuji Yamashita and Masahide SHIOZAWA \\ Department of Anatomy, School of Medicine, Keio University, Shinjuku, Tokyo 160
}

\begin{abstract}
Taking $\gamma$-glutamyl transpeptidase $(\gamma$-GT)-monoclonal anti $\gamma$-GT system as an example, the effect of microwave fixation for the immunohistochemical study was examined in rat kidney, pancreas, duodenum and liver, using a domestic microwave oven. The results were compared with that of the previous study using conventional fixatives. Best results were obtained in tissues irradiated in 4\%-8\% paraformaldehyde containing $10 \%$ glucose or $5 \%-10 \%$ polyethylene glycol 2000 at $45^{\circ}-50^{\circ} \mathrm{C}$. But, the immunoreaction was not demonstratable along the brush border of the duodenum. Though the microwave fixation is a useful tool for immunohistochemistry, it is necessary to adjust the condition of irradiation and the composition of fixatives to keep the physiological state of each organ or tissue well preserved and for the antigen to stay as it is originally located without loosing its antigenicity.
\end{abstract}

Since Mayer (9) reported the possibility of using microwaves for histological fixation, Patterson et al. (11), Hopwood et al. (2), Leong et al. (5), Login et al. $(6,7)$ and Armati et al. (1) showed that microwave fixation was effective in the use of immunohistochemical studies. Some of these studies were carried out on the light microscopic level and others on the electron microscopic level. The results of these studies with microwave fixation showed that the tissue structure was extremely well preserved and the reactivity of the antigens was retained enough to sustain their binding to their specific antibodies.

The immunohistochemistry is based on only one reaction system, i.e., the antigen-antibody interaction. The modes of immunoreactivity vary depending on the nature of the antigen determinants, the conformation of the various antigen molecules, the location of the antigens in tissues, the sensitivity of the antigen to microwave and to other physical circumstances, the grade of the retention of antigenicities after chemical fixations, the structure of the tissue in which the target antigen is present, and the chemical tissue constituents which surround the antigen molecules. For this reason, the condition of the microwave fixation is required to be fixed each time for each antigen to be studied in an immunohistochemical study.

The present study dealt with the basic examination on the conditions of microwave fixation usable for immunohistochemical studies, taking $\gamma$-GT-monoclonal anti $\gamma$-GT system as a model example. Furthermore, the results were compared with those obtained with the conventional fixation process reported in the previous study (14). 


\section{MATERIALS AND METHODS}

Tissue preparation for light microscopy

Rat kidney, pancreas, liver and duodenum were used in this study. They were taken under Nembutal anesthesia, cut into small pieces (approximately $0.3 \mathrm{cubic} \mathrm{cm}$ ) and immersed in the fixatives. After microwave irradiation under several experimental conditions which will be described below, tissues were dehydrated with graded ascending series of ethanols, cleared in xylene and embedded in paraffin. Paraffin sections of $5 \mu \mathrm{m}$ thickness were subjected to further immunoreaction.

Fixatives

Following fixatives were examined;

$2 \%$ or $4 \%$ paraformaldehyde (PFA)

$0.05-1 \%$ glutaraldehyde $(\mathrm{G})$

periodate-lysine-paraformaldehyde (PLP) (8)

mixture of equal volume of $4 \% \mathrm{PFA}$ and $0.5 \% \mathrm{G}$

$4 \%$ PFA containing $1 \%, 5 \%$ or $10 \%$ polyethylene glycol 1000,2000 or 4000

$4 \%$ PFA containing $1 \%, 5 \%$ or $10 \%$ glucose

$8 \%$ PFA containing $1 \%, 5 \%$ or $10 \%$ polyethylene glycol 400,1000 and 2000

All the fixatives were prepared in $0.1 \mathrm{M}$ sodium cacodylate buffer, $\mathrm{pH} 7.4$ which contained $0.025 \% \mathrm{CaCl}_{2}$.

Microwave fixation

A domestic microwave oven (Model EM-A500T, Sanyo Electric Co., Osaka) was used, operating at $2450 \mathrm{MHz}$ with heat setting at 500 watts output. A $250 \mathrm{ml}$ water load at room temperature was placed in a corner of chamber. The tissue blocks immersed in $3 \mathrm{ml}$ of the fixative in a flat container were irradiated for 15-120 sec. The temperature of the fixative was measured at the bottom of the container just after the irradiation.

Immunohistochemistry

A monoclonal antibody against rat kidney $\gamma$-GT (14) was placed onto $5 \mu \mathrm{m}$ thick paraffin sections, which were pretreated with $1 \%$ bovine serum albumin (BSA) for blocking. After $2 \mathrm{hr}$, sectioins were washed and treated with biotinylated antibody and ABC complex (3). Peroxidase activity was detected by diaminobenzidine reaction. For the control immunohistochemical staining, the 1st antibody was replaced by phosphate buffered saline (PBS) to get a negative reaction.

Histochemistry

Frozen sections of microwave-irradiated tissues were prepared and stained for $\gamma$ GT by the azo dye technique (12) to compare the results with those obtained by immunoreaction.

\section{Electron microscopy}

Blocks of kidney were immersed in $8 \%$ PFA dissolved in $0.1 \mathrm{M}$ sodium cacodylate buffer ( $\mathrm{pH} 7.4$ ) containing $0.025 \%$ calcium chloride and $10 \%$ polyethylene glycol. After irradiation, thin slices of tissue were prepared by use of Microslicer (Dosaka Co., Osaka). The slices were then reacted with monoclonal anti $\gamma$-GT antibody, washed and immunostained with ABC method (3). After the diaminobenzidine reaction, slices were washed, fixed with $2 \%$ osmium tetroxide, dehydrated in graded ethanols and embedded in epon. Ultra-thin sections were cut on a ultramicrotome, and the sections were observed with JEOL $100 \mathrm{CX}$ electron 
microscope without electron staining.

\section{RESULTS}

Duration of microwave irradiation

The microwave fixation was performed within the range of $15-120$ seconds. A preliminary test with the oven showed that the temperature reached $65^{\circ} \pm 5^{\circ} \mathrm{C}$ with 120 seconds irradiation, when the initial temperature of the fixative was $0^{\circ} \mathrm{C}$, $45^{\circ} \mathrm{C} \pm 2{ }^{\circ} \mathrm{C}$ with 15 seconds irradiation, when the initial temperature of the fixative was $18^{\circ} \mathrm{C}$. Even though excellent histological structure and immunohistochemical reaction were observed in 120-seconds experiment in the kidney (Fig. 1), the condition of 17 -second irradiation $\left(45^{\circ} \mathrm{C}-50^{\circ} \mathrm{C}\right)$ was used throughout the course of this study. General strategy

Results of the pilot studies on the preservation of the histological structure, histochemical reaction and immunohistochemical reactivity in rat kidney, pancreas and duodenum, using following fixatives are shown in Table 1,

1. $4 \% \mathrm{PFA}$ in $0.1 \mathrm{M}$ cacodylate buffer, $\mathrm{pH} 7.4$, containing $0.025 \% \mathrm{CaCl}_{2}(\mathrm{PFA})$,

2. $2 \% \mathrm{PFA}$ and $0.05 \% \mathrm{G}$ in $0.1 \mathrm{M}$ cacodylate buffer, $\mathrm{pH} 7.4$, containing $0.025 \% \mathrm{CaCl}_{2}(\mathrm{PFA}+\mathrm{G})$,

3. $1 \% \mathrm{G}$ in $0.1 \mathrm{M}$ cacodylate buffer, $\mathrm{pH} 7.4$, containing $0.025 \% \mathrm{CaCl}_{2}(\mathrm{G})$, 4. PLP

The results summarized in Table 1, were those of the pilot studies designed to

TABLE 1. Pilot studies on the effect of microwave irradiation on several rat tissues.

\begin{tabular}{|c|c|c|c|c|c|c|c|c|c|c|c|c|c|}
\hline & \multirow{2}{*}{$\begin{array}{l}\text { Fixatives } \\
\text { Seconds }\end{array}$} & \multicolumn{3}{|c|}{ PFA } & \multicolumn{3}{|c|}{$\mathrm{PFA}+\mathrm{G}$} & \multicolumn{3}{|c|}{$\mathrm{G}$} & \multicolumn{3}{|c|}{ PLP } \\
\hline & & 15 & 60 & 120 & 15 & 60 & 120 & 15 & 60 & 120 & 15 & 60 & 120 \\
\hline \multirow[t]{3}{*}{ Kidney } & Structure & H & $H$ & H & H & $H$ & H & H & $H$ & H & $H$ & + & + \\
\hline & Histochem & H & H & H & H & $H$ & H & $H$ & H & $H$ & H & H & + \\
\hline & Immunohist & H & + & + & $H$ & H & H & + & H & H & H & H & + \\
\hline \multirow[t]{3}{*}{ Pancreas } & Structure & HH & $H$ & H & + & H & $H$ & H & H & H & + & + & H \\
\hline & Histochem & \pm & + & + & - & + & + & - & + & - & - & - & + \\
\hline & Immunohist & - & - & \pm & - & - & - & - & - & - & - & - & H \\
\hline \multirow[t]{3}{*}{ Duodenum } & Structure & H & H & H & $H$ & H & m & H & H & H & + & $H$ & H \\
\hline & Histochem & + & - & - & - & - & - & - & - & - & - & - & - \\
\hline & Immunohist & - & - & - & - & - & - & - & - & - & - & - & - \\
\hline \multirow[t]{3}{*}{ Liver } & Structure & \pm & \pm & \pm & \pm & \pm & \pm & \pm & + & + & - & \pm & \pm \\
\hline & Histochem & - & - & - & - & - & - & - & - & - & - & - & - \\
\hline & Immunohist & - & - & - & - & - & - & - & - & - & - & - & - \\
\hline
\end{tabular}

The numbers, 15, 60 and 120 represent the duration of irradiation in seconds. The initial temperature of the fixation at 15 seconds was at room temperature $\left(18^{\circ} \mathrm{C}\right)$, while $0^{\circ} \mathrm{C}$ was used for the 60 -second and 120 -second tests. The temperature of the fixatives at the termination of the irradiation was $45^{\circ}, 55^{\circ}$ and $65^{\circ} \mathrm{C}$, respectively. H: Excellent or strong, H: Good or medium, + : Fair or weak, \pm : Weak to negative, - : Negative. 

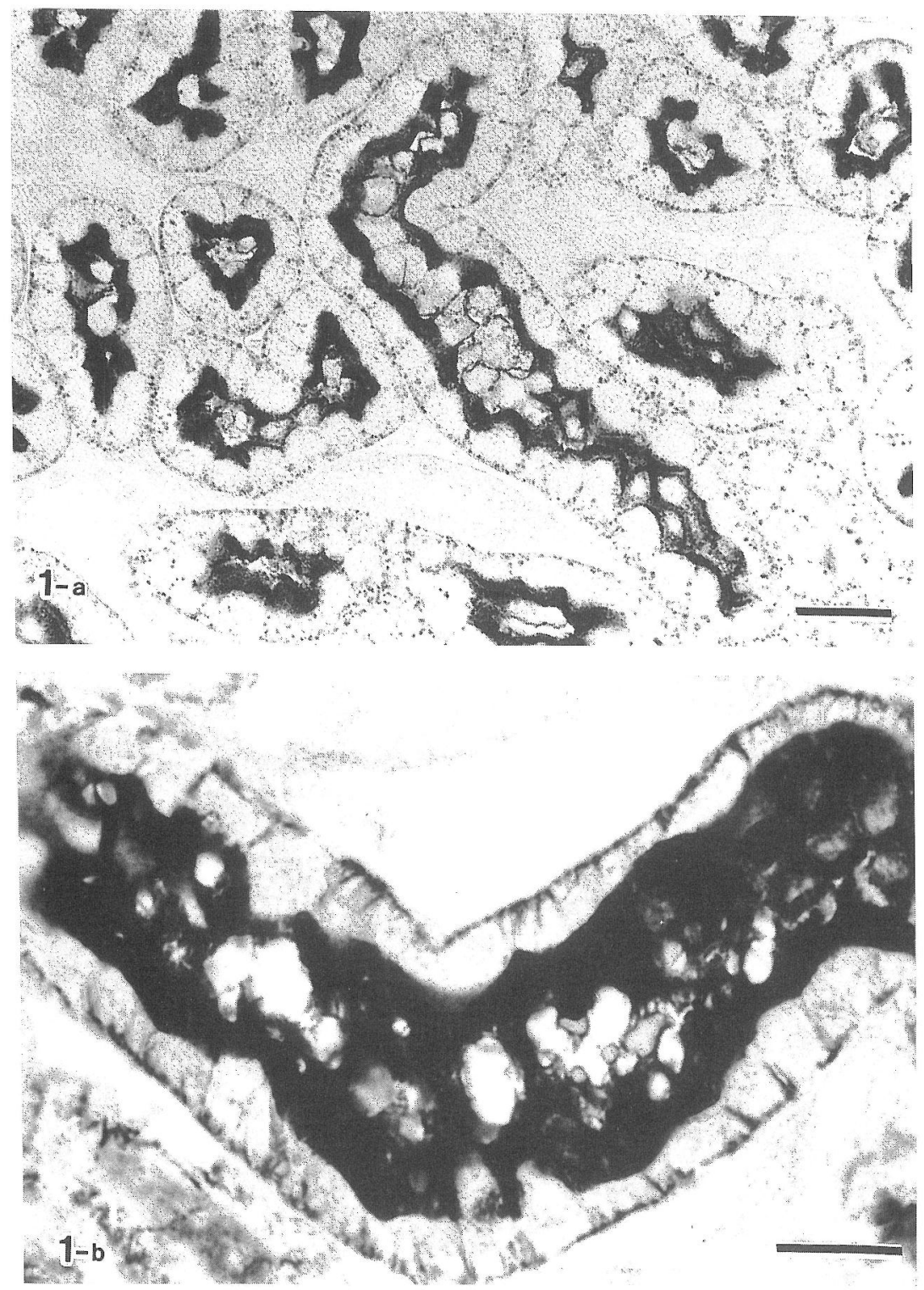

FIG. 1. (a) Rat kidney irradiated for 120 seconds $\left(65^{\circ} \mathrm{C}\right)$ in $1 \%$ glutaraldehyde. Temperature of the fixative was $0^{\circ} \mathrm{C}$ at the initiation of irradiation. Reaction is recognized on the brush border and along the basolateral membrane. But, the reaction products deposited along the basolateral membrane are granulated. However, in the kidney fixed with a conventional process using $4 \%$ paraformaldehyde (b), reaction products are smooth along the basolateral membrane. Original magnifications: $\mathrm{a} \times 380, \mathrm{~b} \times 1,575 \quad \mathrm{Bar}: \mathrm{a}=30 \mu \mathrm{m}, \mathrm{b}=10 \mu \mathrm{m}$ 

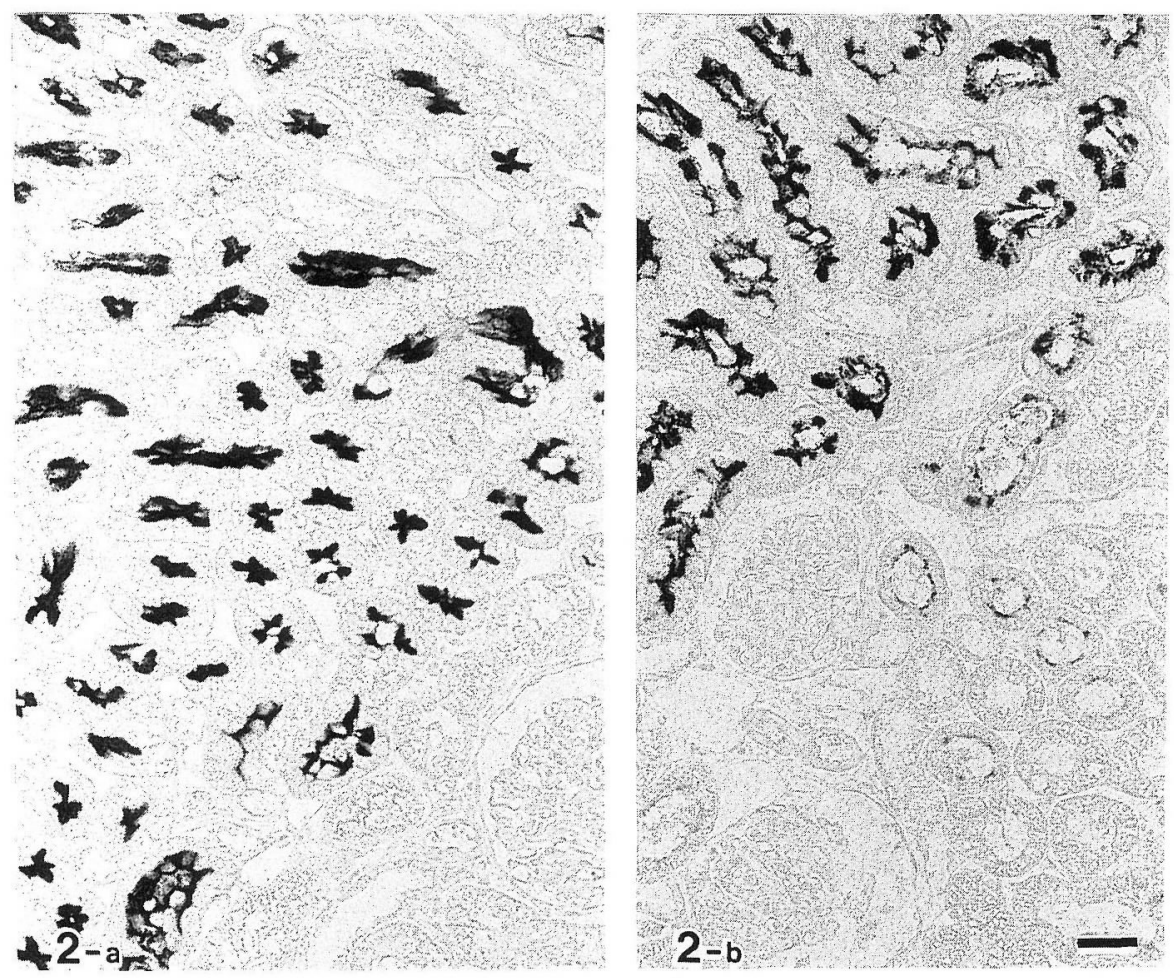

FIG. 2. (a) Rat kidney immunostained for $\gamma$-GT after irradiation for 15 seconds with microwave in 4\% paraformaldehyde. Reaction is confined to brush border of the proximal tubules. Most of lumens are closed. Lower light corner of the photograph is not well fixed. (b) Most of lumens are open. Reaction in the tubules at lower right corner is weaker than that in the other portions, suggesting that the irradiation was uneven. Original magnifications $\times 190 \quad \mathrm{Bar}=30 \mu \mathrm{m}$

find out appropriate conditions in microwave fixation. It was found that the histological structure seemed to be well preserved, almost regardless of the varieties of the fixing conditions. However, looking at the sections precisely, several abnormal or damaged feature were recognized.

1. Kidney: The lumens of some proximal tubules, both convoluted and straight portions, were left open, while others closed (Fig. 2). The epithelial cells of some proximal tubules were exfoliated. The immunoreaction along the brush border was strong, but was not recognized along the basolateral membrane of the proximal tubules. Also, the fixation effect was not uniform in a section after short irradiation. 2. pancreas: The preservation of the structure of the acinar cells was fairly good. But the distance between each acinus and that between each lobule was abnormally wide. The cluster of zymogen granules was not well defined after long irradiation. Almost no immunoreaction was seen along the apical cell surface, except in the tissue irradiated for 120 seconds in PLP fixative.

3. Duodenum: The lumen of the blood vessels in lamina propria was wide open at 
TABLE 2. Results obtained by adding glucose (GLC) or polyethylene glycol (PEG) to paraformaldehyde (PFA).

\begin{tabular}{|c|c|c|c|c|c|c|c|c|}
\hline \multirow{2}{*}{ Tissues } & \multirow{2}{*}{$\begin{array}{c}\text { Additives } \\
\text { Conc. } \\
\end{array}$} & \multicolumn{3}{|c|}{ GLC (added to $8 \%$ PFA) } & \multicolumn{4}{|c|}{ PEG (added to $8 \% \mathrm{PFA}$ ) } \\
\hline & & $1 \%$ & $5 \%$ & $10 \%$ & $5 \%$ PEG 400 & 5\%PEG100n & 5\%PEG2000 & 10\%PEG2000 \\
\hline \multirow[t]{3}{*}{ Kidney } & Structure & H & H & H+ & H & $H$ & H & H+ \\
\hline & Histochem & H & $H^{*}$ & H & $\mathrm{H}^{*}$ & $H^{*}$ & $H^{*}$ & $\mathrm{H}^{*}$ \\
\hline & Immunohist & + & + & $H^{*}$ & $H$ & $H$ & $H^{*}$ & $\mathrm{H}^{*}$ \\
\hline \multirow[t]{3}{*}{ Pancreas } & Structure & H & H & H+ & H & H & H & $\mathrm{H}^{*}$ \\
\hline & Histochem & + & H & $H^{*}$ & - & + & $H^{*}$ & $H^{*}$ \\
\hline & Immunohist & \pm & + & H & + & + & $H^{*}$ & $H^{*}$ \\
\hline \multirow[t]{3}{*}{ Duodenum } & Structure & + & H & $H^{*}$ & H & H & HH & H \\
\hline & Histochem & - & - & - & - & - & $H^{*}$ & $H^{*}$ \\
\hline & Immunohist & - & - & - & - & - & - & - \\
\hline \multirow[t]{3}{*}{ Liver } & Structure & + & H & $H^{*}$ & H & H & H & $H^{*}$ \\
\hline & Histohem & - & - & - & - & - & - & - \\
\hline & Immunohist & - & - & - & - & - & - & - \\
\hline
\end{tabular}

Irradiation: 15 second $\left(45^{\circ} \mathrm{C} \pm 2^{\circ} \mathrm{C}\right)$. $\mathrm{H}^{*}$ : The conditions suitable for practical use.
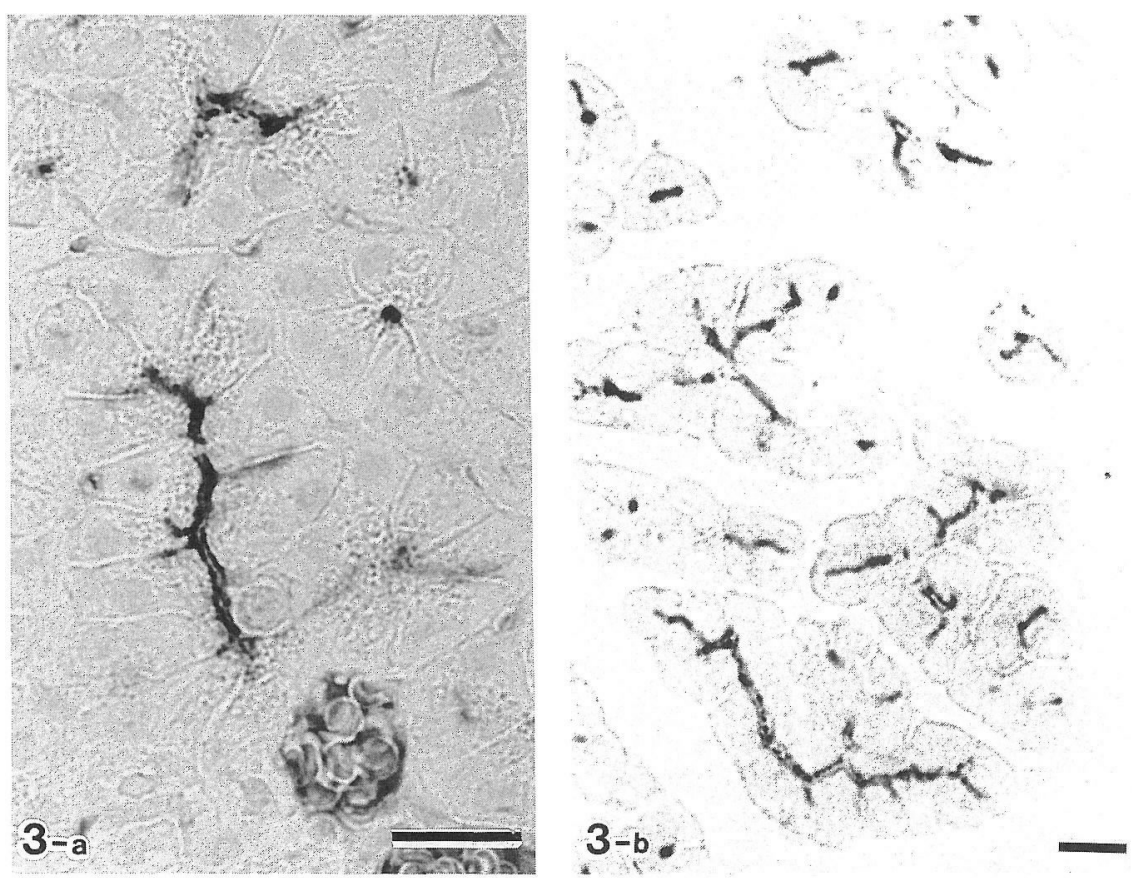

FIG. 3. (a) Rat pancreas irradiated for 17 seconds in $8 \%$ paraformaldehyde containing $10 \%$ polyethylene glycol. Immunoreaction is recognized along the apical cell surface. Reaction pattern is the same as with the conventional fixation (b). Original magnifications: $\mathrm{a} \times 680, \mathrm{~b} \times 340$ Bars $=20 \mu \mathrm{m}$ 

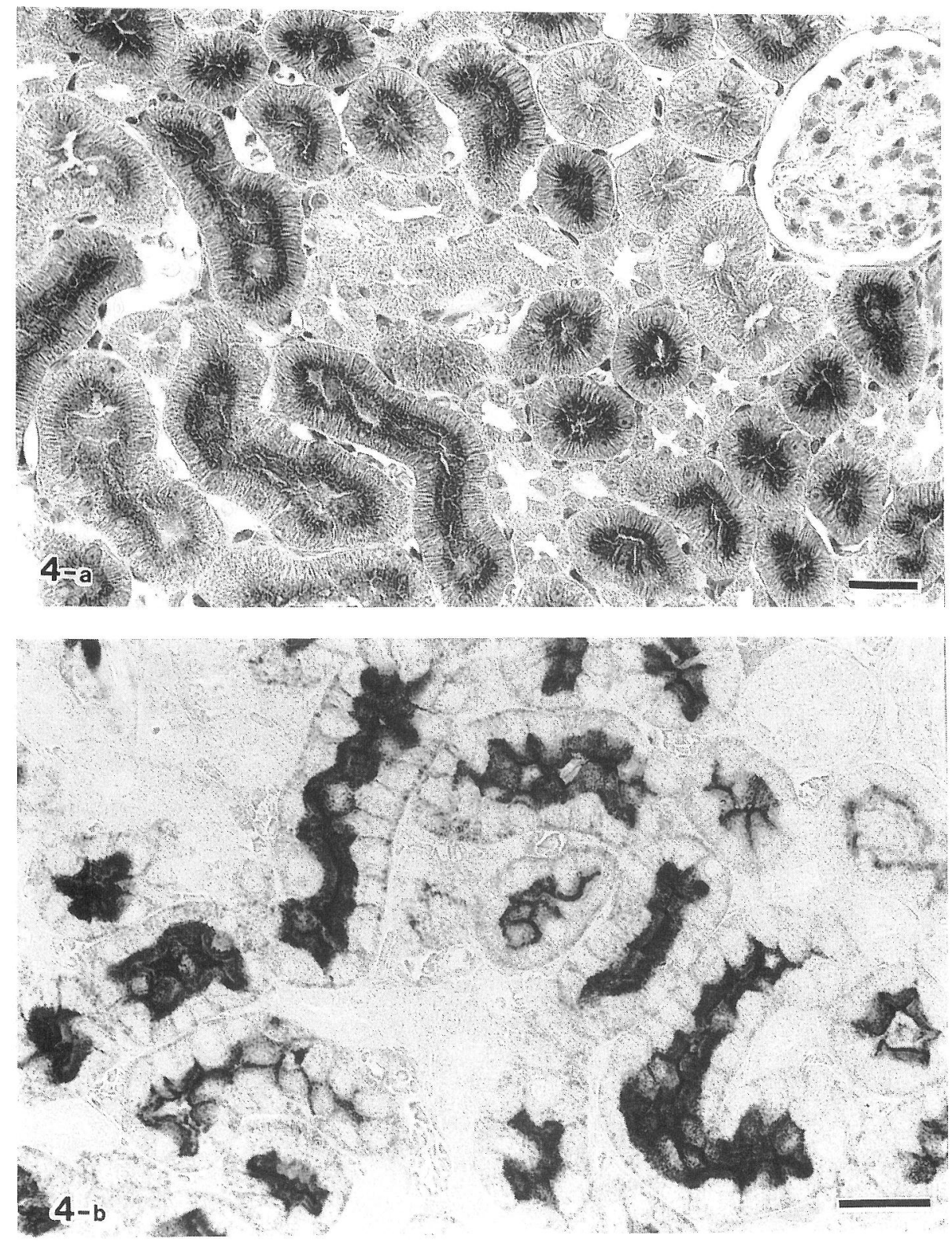

FIG. 4. (a) Enzyme histochemical reaction by use of azo dye method in rat kidney. Fixation process is the same as in Fig. 3-a. (b) Immunoreaction pattern in kidney with the same fixation process as in (a). Original magnifications: $\mathrm{a} \times 340, \mathrm{~b} \times 370 \quad$ Bars $=30 \mu \mathrm{m}$ 

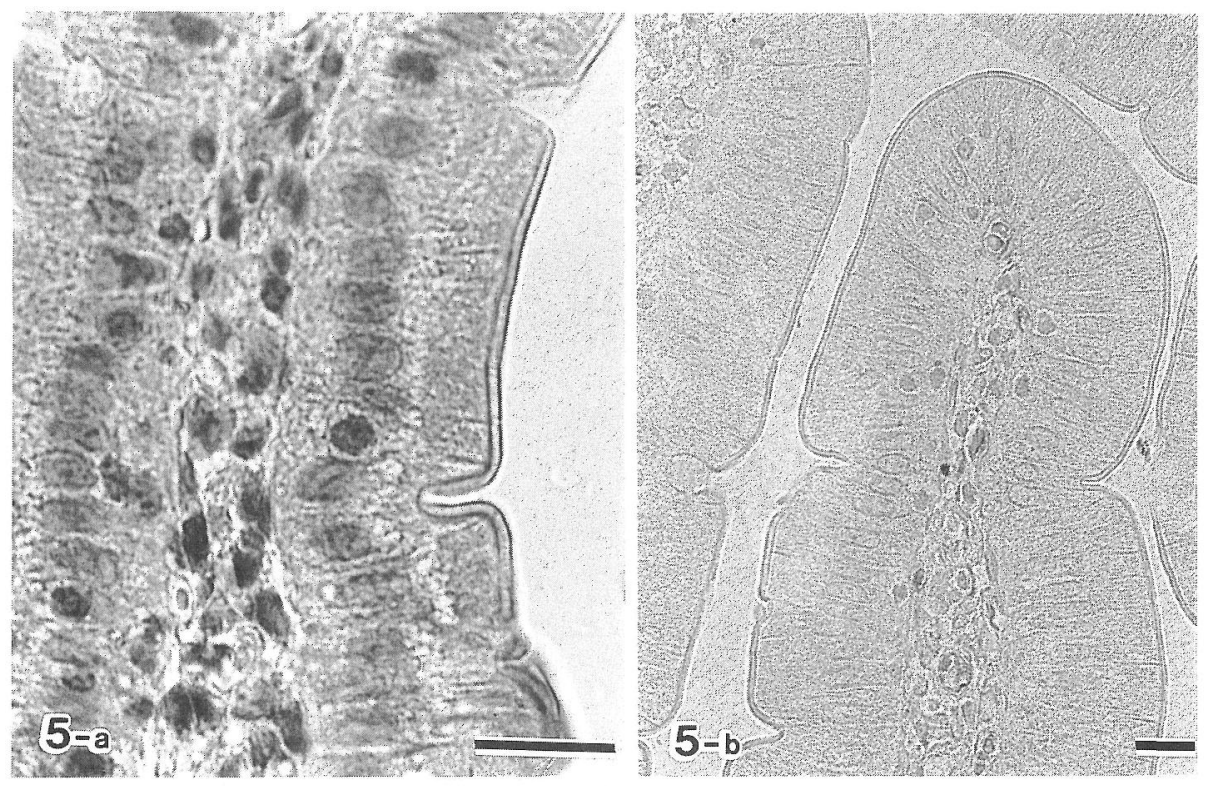

FIG. 5. Rat duodenum fixed with microwave under the same conditions as in Fig. 3a. Brush border shows positive reaction with azo dye method (a). However, no immunoreaction is seen (b). Original magnifications: $\mathrm{a} \times 700, \mathrm{~b} \times 310 \quad \mathrm{Bars}=20 \mu \mathrm{m}$

the lower part of an intestinal villus. No Immunoreaction was observed along the brush border.

4. Liver: The cytoplasm was highly vacuolated. No immunoreaction was observed.

Taking the results of the pilot studies in consideration, the fixation with PFA for 17 seconds $\left(45^{\circ}-50^{\circ} \mathrm{C}\right)$ was decided to be used for further studies. Paying attention to the abnormal or damaged features mentioned above, experiments were continued to improve the histological structure and the reactivity in both enzyme histochemistry and immunohistochemistry.

Concentration of $P F A$

Among 2\%, 4\% and $8 \%$ PFA, the use of $8 \%$ was found to be best. Fixation with $4 \%$ is also usable.

Selection of additive materials to PFA

Glucose (GLG) and polyethylene glycol (PEG) were examined. These were added to $8 \% \mathrm{PFA}$ at the ratio of $1 \%, 5 \%$ and $10 \%$, respectively. The results are summarized in Table 2.

Addition of $10 \%$ glucose, $5 \%$ or $10 \%$ polyethylene glycol to $8 \%$ PFA or $4 \%$ PFA provided excellent preservation of histological structure and reactions both in enzyme histochemistry and immunohistochemistry in pancreas (Fig. 3) and kidney (Fig. 4). However, the brush border of duodenum was reactive to the azo dye method but not reactive to the antibody (Fig. 5). Liver was also negative in immunoreaction. But the rat liver was also negative with conventional fixation. Blood vessels showed 

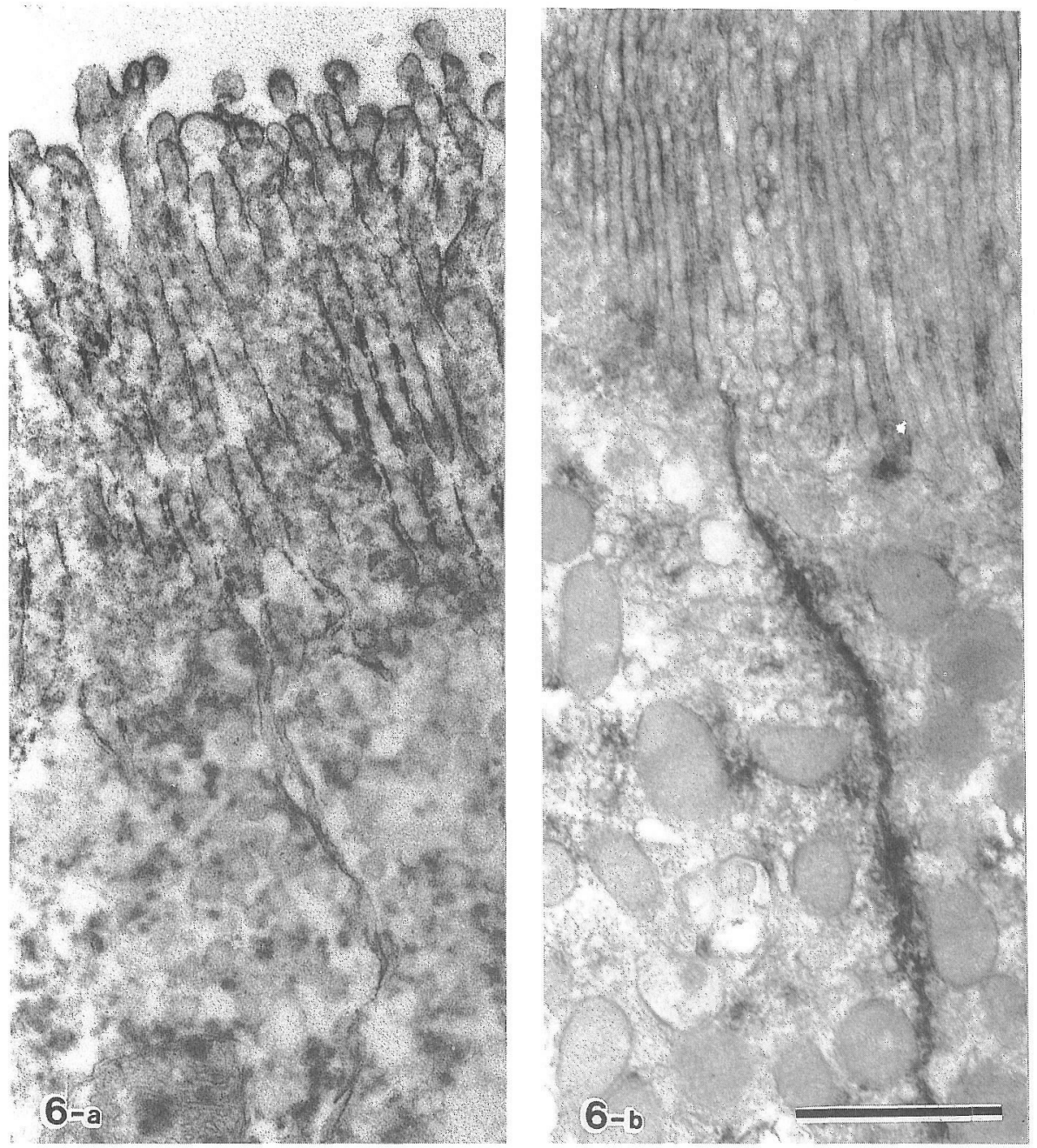

FIG. 6. Electron micrographs of the apical area of the cells in the proximal tubule of rat kidney. (a) A section of kidney fixed with microwave under the same conditions as in Fig. 3a. Immunoreaction on the microvilli and along the lateral membrane is clearly visible. However, the parallel arrangement of microvilli is disrupted, the cytoplasm is partly disordered and granulated irregular dark spots are seen in the cytoplasm, compared with the sections treated with the conventional fixation process. (b) Original magnifications $\times 24,000 \quad$ Bar $=1 \mu \mathrm{m}$

peculiar reaction pattern. The amorphous material in the blood vessels often demonstrated strong diaminobenzidine reaction (Fig. 3). The reaction was recognized also along the endothelial cells of the blood vessels. This reaction was also noticed in the control sections, in which PBS was used in place of the specific antibody. Container and volume of the fixative

In principle, any container made of glass or plastic materials may be used. It 
was clear that use of a small and flat container with a small amount of the fixative (e.g. $3 \mathrm{ml}$ ) results in shorter irradiation period (data not shown).

Electron microscopy (Fig. 6)

In the examination with a elctron microscope, the antigen, $\gamma$-GT was well localized along the microvilli of the brush border of the proximal tubule of the kidney. The reaction product is also recognized along the lateral membrane of the epithelial cells. The reaction was even stronger than that recognized in the specimens prepared with the conventional fixatives. However, the structure in the cytoplasm was not well preserved. Some holes with irregular sizes and clefts were observed, and the arrangement of microvilli was disordered.

\section{DISCUSSION}

Microwave fixation is expected to be a useful tool for immunohistochemical study because of its rapid effect, under the condition that the temperature of the fixatives at the termination of irradiation is adequately regulated and the fixatives and the additives are properly selected. The temperature of the fixative is regarded as more important than the duration of the irradiation, even though the exact temperature within tissue blocks is impossible to measure at this point.

As already described, the best result was obtained at $45^{\circ}-50^{\circ} \mathrm{C}$, when the initial temperature of the fixative was room temperature. This result coincides with those reported in previous papers (6.7), but not with others. Patterson et al. (10) fixed the cultured cells for less than 10 seconds, under the condition that the irradiation takes 16 seconds to rise $50 \mathrm{ml}$ water to $60^{\circ} \mathrm{C}$, in order to demonstrate transglutaminase and fibronectin. Hopwood et al. (2) fixed brain tissue at $60^{\circ} \mathrm{C}$ to show the localization of globulins and Leong et al. (5) used $21^{\circ}-23^{\circ} \mathrm{C}$ to localize lymphocyte antigens in the tonsil. In the present experiment, fairly good immunoreaction for $\gamma$-GT was obtained in the rat kidney even at $65^{\circ} \mathrm{C}$, after irradiating the fixative cooled at $0^{\circ} \mathrm{C}$ for 120 seconds. Thus, the optimal temperature seemed to be variable, depending on the variety of organs and the antigens to be studied.

Concerning the duration of irradiation to obtain a suitable fixation effect, the statements in the previous papers $(1,2,4,6,11)$ are different from each other. In the present study, the irradiation was tried for 15,60 and 120 seconds in the pilot study. As a result, the irradiation time was standardized to 17 seconds to reach $45^{\circ}-50^{\circ} \mathrm{C}$. Nevertheless, good results were also obtained in the kidney even after 120 second-irradiation. Since the fixation with microwave is thought to be mainly due to its rapid heating effect caused by dielectric vibration of the water molecule, it is more important for fixatives to reach required temperature as quickly as possible than to be irradiated for a fixed period. The duration also varies depending on the power and operating frequency of the oven used. Thus, it may not be too important to lay excessive emphasis on the variation of the time sequence in the iradiation, even if the duration reported in each previous experiment differs from each other.

The histological structure is excellent, in general, under adequate conditions. As far as the localization pattern of $\gamma$-GT is concerned, an immunohistochemical feature in kidney and pancreas is clear as if they were treated with conventional fixatives (14), when 4-8\% PFA containing containing $10 \%$ glucose or $5-10 \%$ polyethylene glycol are used as additives. Under this condition, the lumen of the prox- 
imal tubules were wide open. However with lower concentration of the fixatives containing no additives, most of the lumens remain closed. It has been well known that the lumen of the proximal tubule is closed with an immersion fixation, while it is open with a perfusion fixation. The feature of the lumen observed in this experiment does not necessarily coincide with that empirically accepted. At present, the reason for this phenomenon remains unknown.

On the other hand, the bile canaliculus of the rat liver was also unreactive under the same conditions as the kidney and pancreas studies. The bile canaliculus was also negative even by using conventional fixative. This is because the amount of $\gamma$-GT in normal rat liver is so small that the antigen along the bile canaliculi is not detectable by an immunohistochemical technique, though immunoreaction is positive in pathological or regenerating states (13). The brush border of the duodenum was also unreactive even under conditions suitable for studies in kidney and pancreas. Login et al. (6) also reported that the stratified squamous epithelia were poorly reactive to the antibody against the epithelial membrane antigen. These facts suggest that the antigen on the surface of the cells facing large open space may be more or less lost or tend to be denaturated during the microwave irradiation. The feature of the liver after microwave fixation was conspicuous. The cytoplasm was highly vacuolated after the irradiation in PFA, G or PLP under certain conditions. This phenomenon was also reported by Mizuhira (10) and Yasuda (15). Mizuhira found that this feature was caused by the outflow of glycogen from cytoplasm, and he succeeded in keeping the outward flow of glycogen from the liver by adding glucose to the fixative. In the present study, the addition of GLC or PEG was successful not only in preserving good histological structures of the liver but also in obtaining enough histochemical as well as immunohistochemical reactions, with an exception of the cases of the liver and the duodenum. The addition of some kind of the supporting media with high molecular weight to rise the osmorality of the fixatives may protect the tissue from excess vibration of the water molecule.

The conditions described in this study can be applied to localize other antigens in different kinds of tissues. However, it is worthy of note that $\gamma$-GT examined in this study is one of the heat-resistant proteins, and that the antibody used is a monoclonal antibody which recognizes only one determinant in the antigen molecule. In order to use microwave for tissue fixation, further close examination will be necessary to find the conditions which are suited for obtaining good histological structure and for preserving the antigenicity of the substance to be studied.

Fixation of tissues by use of microwave irradiation in the solution containing no fixatives was successfully studied by Patterson et al. (16), Hopwood et al. (2) and Leong et al. (5) on various tissues for the immunohistochemical demonstration of different kinds of antigens. However, Leong et al. (4) noticed some difficulties in preserving fine structure of cell organelles, such as swelling of mitochondria and disruption of cristae, in the study with electron microscope. In the present study, the fixation only with microwave irradiation was not carried out. But, this process is expected to be usable to localize the antigens which lose their antigenicity with chemical fixative and are relatively resistant to a temperature slightly above body temperature, if the solution is appropriately prepared.

The deposit of diaminobenzidine reaction product is seen in the blood vessels in many organs. This is of non-specific in nature, since it is noticed even in the control 
sections. The reaction may be due to hemoglobin produced by the rupture of erythrocytes.

Observation with electron microscope showed that $\gamma$-GT was fairly well demonstrated along the brush border and the lateral membrane of the epithelial cells of kidney proximal tubule. Moreover, the reaction was even stronger than with the conventional fixation. However, there were some disorders in the structural detail. Though the reaction was positive along the membrane, the brush border is known as the site where $\gamma$-GT is highly concentrated. Therefore, the antigen was demonstrable even after microwave fixation because it is highly concentrated. As for the disorder in the cell structure, Leong (4) has already pointed this out. At present, the conventional fixation has an advantage over microwave fixation. Further improvement is required for the application of microwave fixation to immunoelectron microscopy.

In conclusion, microwave fixation is a useful tool for the study of immunochemistry because of its rapid effect, if the fixation process is carried out under suitable conditions for the tissues and the antigens to be studied. One condition is not always suitable for every organ and tissue. Further precise investigation is required to examine fine structures of tissues and the reactivity of antigens with electron microscope.

\section{ACKNOWLEDGEMENTS}

The authors appreciate the assistance of Mr. Takeuchi for preparing specimens. This study was supported in part by a Grant-in-Aid for Scientific Research from the Ministry of Education, Science and Culture, Japanese Government No. 61840093.

\section{REFERENCES}

1. Armati, P. J., Pollard, J. D., Van Reyk, D. and Van der Lubbe, L.: Neuroimmunological electron micrscopy with microwave-accelerated fixation. J. Immunol. Meth. 110; 267-269, 1988.

2. Hopwood, D., Coghill, G., Ramsay, J., Milne, G. and Kerr, M.: Microwave fixation: its potential for routine techniques, histochemistry. Immunochemistry and electron microscopy. Histochem. J. 16; 1171-1191, 1984.

3. Hsu, Su-Ming, Raine, L. and Fanger, H.: Use of avidin-biotin-peroxidase complex (ABC) in immunoperoxidase techniques: A comparison between $\mathrm{ABC}$ and unlabeled antibody (PAP) procedures. J. Histochem. Cytochem. 29; 577-580, 1981.

4. Leong, A. S.-Y., Daymon, M. E. and Milios, J.: Microwave irradiation as a form of fixation for light and electron microscopy. J. Path. 146; 313-321, 1985.

5. Leong, A. S.-Y. and Milios, J.: Rapid immunoperoxidase staining of lymphocyte antigens using microwave irradiation. J. Path. 148; 183-187, 1986.

6. Login, R. G., Schnitt, S. J. and Dvorak, A. M.: Methods in laboratory investigation. Rapid microwave fixation of human tissues for light microscopic immunoperoxidase identification of diagnostically useful antigens. Lab. Invest. 57; 585-591, 1987.

7. Login, R. G., Galli, S. J., Morgen, E., Arizono, N., Schwarz, L. B. and Dvorak, A. M.: Rapid microwave fixation of rat mast cells. I. Localization of granule chymase with an ultrastructural postembedding immunogold technique. Lab. Invest. 57; 592-599, 1987.

8. McLean , I. W. and Nakene, P. K.: Periodate-lysine-paraformaldehyde fixative. A new fixative for immunoelectron microscopy. J. Histochem. Cytochem. 22; 1077-1083, 1974. 
9. Mayer, C. P.: Histological fixation by microwave heating. J. Clin. Path. 23; 273-275, 1970.

10. Mizuhira, V., Hasegawa, H. and Notoya, M.: Tissue-fixation with microwave. II. Application to histocytochemistry (1). Abstract of the 29th annual Meeting of the Japan Sciety of Histochemistry and Cytochemistry, 1988, p. 121 (in Japanese).

11. Patterson, Jr, M. K. and Bulard, R.: Microwave fixation of cells in tissue culture. Stain Tech. $55 ; 71-75,1980$.

12. Rutenburg, A. M., Kim, H., Fishbein, J. W., Hanbeer, J. S., Wasserkrug, H. L. and Seligman A. M.: Histochemical and ultrastructural demonstration of $\gamma$-glutamyl transpeptidase activity. J. Histochem. Cytochem. 17; 517-526, 1969.

13. Shiozawa, M., Aiso, S., Hosiai, O., Taharo, H., Yamashita, S. and Yasuda, K.: Localization of gammaglutamyl transpeptidase in the proliferative state of liver. An enzyme histochemical and immunohistochemical study. Okajimas Fol. Anat. Jpn. 63; 209-222, 1986.

14. Yasuda, K., Yamashita, S., Aiso, S., Shiozawa, M. and Komatsu, T.: Immunohistochemical study of $\gamma$-glutamyl transpeptidase with monoclonal antibodies. 1. Preparation and characteristics of monoclonal antibodies to $\gamma$-glutamyl transpeptidase. Acta histochem. cytochem. 19; 589-600, 1986.

15. Yasuda, K.: Recent advance in immunohistochemistry. Abstract of the 29th Annual Meeting of the Japan Society of Histochemistry and Cytochemistry, 1988, p. 35 (in Japanese).

Addendum:

After submitting the paper, we noticed that the following recent literatures were missing from the refferences;

* Mizuhira, V.: fixation of biological specimens by microwave irradiation. Pure Chemical "Daiichi" 19; 103-116, 1988 (in Japanese).

* Microwave cookbook of pathology. The art of microscopic visualization. ed. by M. E. Boon and L. P. Kok, Coulomb Press Lyden, Lyden, 1987. 